\title{
Original Article \\ The Effect of Different Extraction Procedures on Antioxidant Activity of Garlic (Allium sativum L.) Essential Oil
}

\author{
Nguyen Van Khanh ${ }^{1,}$, Do Thi Nhai ${ }^{1}$, Bui Thanh Tung ${ }^{1}$, Nguyen Thanh Hai ${ }^{1}$ \\ ${ }^{l}$ VNU School of Medicine and Pharmacy, 144 Xuan Thuy, Cau Giay, Hanoi, Vietnam
}

Received 23 February 2020

Revised 03 March 2020; Accepted 10 March 2020

\begin{abstract}
This paper studies the effect of different extraction procedures such as soxhlet extraction using n-hexane, distillation method and supercritical extraction (SFE) on the physicochemical properties of garlic essential oil. The yield of garlic essential oil by soxhlet extraction, steam distillation and SFE- $\mathrm{CO}_{2}$ methods was approximately $0.441,0.124$ and $0.465 \%$, respectively. The results of the oil analysis by gas chromatography/mass spectrometry method show the presence of five major compounds, including diallyl sulfide, diallyl disulfide, 3-vinyl-1,2-dithiacyclohex-4-ene, 3 -vinyl-1,2-dithiacyclohex-5-ene and diallyl trisulfide. The antioxidant activity of the essential oil obtained by the SFE- $\mathrm{CO}_{2}$ method was significantly higher than by the distillation method, but was lower than the acid ascorbic one.
\end{abstract}

Keywords: Garlic essential oil, SFE, GC-MS, antioxidant activity, extraction.

\footnotetext{
* Corresponding author.

E-mail address: khanha7k64dkh@ gmail.com

https://doi.org/10.25073/2588-1132/vnumps.4213
} 


\title{
Nghiên cứu chiết xuất và đánh giá tác dụng chống oxy hóa của tinh dầu tỏi từ củ tỏi (Allium sativum L.)
}

\author{
Nguyễn Văn Khanh ${ }^{1, *}$, Đỗ Thị Nhài ${ }^{1}$, Bùi Thanh Tùng ${ }^{1}$, Nguyễn Thanh Hải ${ }^{1}$ \\ ${ }^{1}$ Khoa Y Dược, Đại học Quốc gia Hà Nội, 144 Xuân Thủy, Cà̀u Giấy, Hà Nội, Việt Nam \\ Nhận ngày 23 tháng 02 năm 2020 \\ Chỉnh sửa ngày 03 tháng 3 năm 2020; Chấp nhận đăng ngày 10 tháng 3 năm 2020
}

\begin{abstract}
Tóm tắt: Tỏi (Allium sativum L.) là một loài có vai trò rất quan trọng trong chi hành (Allium) được tiêu thụ trên toàn thế giới. Các allicin (diallyl disulfid, diallyl trisulfid) có trong tinh dầu tỏi thể hiện tác dụng kháng khuẩn và chống oxy hóa tốt. Mục đích của nghiên cứu này là nghiên cứu sự ảnh hưởng của các phương pháp chiết xuất khác nhau như chiết soxhlet với n-hexan, cất kéo hơi nước, chiết xuất bằng dung môi $\mathrm{CO}_{2}$ siêu tới hạn tới tính chất lý hóa của tinh dầu tỏi. Hiệu suất chiết xuất của các phương pháp chiết soxhlet, cất kéo hơi nước, chiết xuất bằng dung môi $\mathrm{CO}_{2}$ siêu tới hạn tương ứng lần lượt là 0,$441 ; 0,124$ và $0,465 \%$. Kết quả phân tích bằng sắc ký khí ghép nối khối phổ cho thấy tinh dầu tỏi gồm 5 chất chính là diallyl sulfid, diallyl disulfid, 3-vinyl-1,2-dithiacyclohex4-en, 3-vinyl-1,2-dithiacyclohex-5-en, diallyl trisulfid. Tinh dầu được chiết xuất bằng sử dụng dung môi siêu tới hạn cho thấy tác dụng chống oxy hóa cao hơn rất nhiều so với phương pháp cất kéo hơi nước, nhưng thấp hơn acid ascorbic.
\end{abstract}

Tư khóa: Tinh dầu tỏi, siêu tới hạn, sắc ký khí khối phổ, hoạt tính chống oxy hóa, chiết xuất.

\section{Mở đầu}

Từ lâu, tỏi (Allium sativum L.) đã được sử dụng nhiều trong cuộc sống để điều trị một số bệnh như cảm lạnh, ho và hen suyễn [1]. Ngày nay, nền y học hiện đại đã chứng minh tỏi có rất nhiều tác dụng sinh học tốt như kháng khuẩn, kháng nấm, kháng vi rút, chống ung thư, chống oxy hoá, hạ cholesterol trong máu, chống sự kết tập tiểu cầu, hoạt động chống viêm và ức chế tổng hợp cholesterol [2].

Tinh dầu tỏi chứa diallyl trisulfid, diallyl disulfid, propyl disulfid và nhiều hợp chất khác có tác dụng kháng khuẩn và chống oxy hóa mạnh [3] và được chiết xuất từ củ tỏi bằng nhiều phương pháp chiết xuất khác nhau như cất kéo

\footnotetext{
"Tác giả liên hệ.

Địa chỉ email: khanha7k64dkh@gmail.com

https://doi.org/10.25073/2588-1132/vnumps.4213
}

hơi nước, chiết với dung môi hữu cơ, chiết bằng dung môi siêu tới hạn [4].

Trong nghiên cứu này, chúng tôi tiến hành chiết xuất tinh dầu tỏi bằng các phương pháp chiết xuất khác nhau và đánh giá một số đặc tính của tinh dầu tỏi như hình thức, thành phần hóa học và tác dụng chống oxy hóa của tinh dầu chiết xuất được.

\section{Nguyên liệu và phương pháp}

\subsection{Nguyên liệu}

Tỏi Kinh Môn (Hải Dương) được thu hoạch vào tháng 01 năm 2018; 1,1-diphenyl-2picrylhydrazyl; natri sulfat, methanol (Trung 
Quốc), n-hexan, acid ascorbic (Đức), nước tinh khiết, khí $\mathrm{CO}_{2}$ sạch (Việt Nam).

Tá dược và hóa chất đều đạt tiêu chuẩn dược dụng hoặc tinh khiết phân tích.

\subsection{Thiết bi}

Máy đo quang UV-2600 Shimadzu (Nhật Bản), cân phân kỹ thuật Shimadzu (Nhật Bản), cân phân tích AY 129 Shimadzu (Nhật Bản), hệ thống chiết xuất $\mathrm{CO}_{2}$ siêu tới hạn SFE 500 hãng Waters (Mỹ), bếp điện WHM 12012 Daihan (Hàn Quốc), hệ thống sắc kí khí ghép khối phổ GC-MS 2010 Plus Shimadzu (Nhật Bản), hệ thống cất quay Rovapor R- 210 Buchi (Đức).

\subsection{Phuơng pháp nghiên cúu}

\subsubsection{Xủ lý nguyên liệu}

Mẫu tỏi tươi Kinh Môn được bóc vỏ, xay nhỏ bằng máy xay sinh tố để chuẩn bị cho quá trình chiết xuất.

\subsubsection{Các phương pháp chiết xuất tinh dầu tỏi}

Chiết xuất tinh dầu tỏi bằng dung môi $\mathrm{CO}_{2}$ siêu tới hạn $\left(\mathrm{SCO}_{2}\right)$ :

Các yếu tố ảnh hưởng đến quá trình chiết là nguyên liệu, áp suất chiểt, nhiệt độ chiết, tỷ lệ dược liệu/ dung môi, tốc độ dòng của $\mathrm{CO}_{2}$, và thời gian chiết. Trong đó yếu tố thuộc về nhiệt độ và áp suất ảnh hưởng rất lớn tới độ hòa tan của các chất trong dung môi $\mathrm{CO}_{2}$ siêu tới hạn [5]. Tham khảo một số các nghiên cứu trước [6,7], tiến hành khảo sát chiết $200 \mathrm{~g}$ tỏi bằng dung môi $\mathrm{CO}_{2}$ siêu tới hạn ở các điều kiện như sau:

- Áp suất: 100 - 300 bar.

- Nhiệt độ: 35 - $50^{\circ} \mathrm{C}$.

- Tốc độ dòng $\mathrm{CO}_{2}: 10 \mathrm{~g} / \mathrm{phút}$.

- Thời gian chiết xuất: 0 - 150 phút.

Tinh dầu chiết xuất được bảo quản trong tủ lạnh ở $4^{\circ} \mathrm{C}$.

Chiết xuất tinh dầu bằng phương pháp cất kéo hơi nước:

$200 \mathrm{~g}$ tỏi được cho vào nồi thêm $1000 \mathrm{~mL}$ nước sau đó lắp vào hệ thống chưng cất lôi cuốn hơi nước. Sau một khoảng thời gian 3 giờ, tắt bếp để nguội, do tinh dầu nhẹ hơn nước nằm ở phía trên nên xả van để nước chảy ra trước sau đó sẽ thu được tinh dầu. Dùng muối $\mathrm{Na}_{2} \mathrm{SO}_{4}$ để làm khan phần nước còn lẫn trong tinh dầu để thu được tinh dầu nguyên chất. Tỉnh dầu được bảo quản trong tủ lạnh ở $4^{\circ} \mathrm{C}$.

Chiết xuất tinh dầu bằng phương pháp chiết Soxhlet với dung môi n-hexan:

$200 \mathrm{~g}$ tỏi cho vào giấy lọc gói lại rồi cho vào bình chiết, thêm vào bình cầu $200 \mathrm{~mL}$-hexan sau đó lắp vào hệ thống chiết Soxhlet. Sau 6 giờ, tắt bếp để nguội, thu toàn bộ dịch chiết đem cô quay dưới áp suất giảm để loại bỏ $\mathrm{n}$-hexan ở nhiệt độ $40^{\circ} \mathrm{C}$. Đem cân và tính hàm lượng tinh dầu thu được. Tinh dầu được bảo quản trong tủ lạnh ở $4^{\circ} \mathrm{C}$.

2.3.3. Phuoong pháp xác định hiệu suất chiết tinh dầu tỏi

Hiệu suất chiết tinh dầu tỏi được tính theo công thức sau [5,6]:

Hiệu suất chiết $(\%)=\frac{\text { Khối lượng tinh dầu }}{\text { Khối lượng mẫu }} \times 100$

Trong đó: khối lượng tinh dầu là khối lượng chất chiết xuất được (g). Khối lượng mẫu là khối lượng tỏi đem chiết $(\mathrm{g})$.

Các phương pháp đánh giá tinh dầu:

Hình thức: xác định màu sắc, độ trong và mùi của tinh dầu.

Phương pháp xác định các thành phần hóa học chính của tinh dầu:

Thành phần hóa học của tinh dầu tỏi được xác định bằng phương pháp sắc ký khí ghép nối đầu dò khối khổ (GC-MS):

- Chuẩn bị mẫu: lấy chính xác $20 \mu 1$ tinh dầu tỏi cho vào lọ, thêm $1000 \mu \mathrm{l}$-hexan, lắc đều. Sau đó lấy $500 \mu 1$ dung dịch vừa pha cho vào lọ, thêm $2000 \mu \mathrm{l}$ n-hexan, lắc đều tới khi đồng nhất. Dung dịch được lọc qua màng lọc cellulose acetat $0,2 \mu \mathrm{m}$ để chạy sắc ký.

- Điều kiện sắc ký: phân tích GC-MS được tiến hành trên máy SHIMADZU GCMS-QP

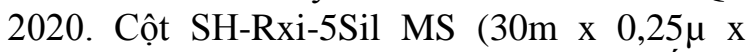
$0,25 \mu$ ). Sử dụng helium làm khí mang với tốc độ dòng khí 1,61 ml/phút, áp suất $100 \mathrm{kPa}$. Nhiệt độ buồng tiêm $250^{\circ} \mathrm{C}$, tỷ lệ chia dòng $1 / 5$, thể tích tiêm $1 \mu 1$. Chương trình nhiệt độ: Nhiệt độ đầu 
$50^{\circ} \mathrm{C}$, tăng $8^{\circ} \mathrm{C} /$ phút đến $270^{\circ} \mathrm{C}$ và giữ trong 3 phút. Ghi nhận khối phổ $\mathrm{m} / \mathrm{z}$ trong khoảng từ 30 - 500, nhiệt độ nguồn ion: $200^{\circ} \mathrm{C}$, nhiệt độ interface: $250^{\circ} \mathrm{C}$. Thư viện phổ NIST 11 được sử dụng để định tính các thành phần hóa học của tinh dầu.

- Kết quả: hàm lượng \% của chất $\mathrm{A}$ trong mẫu phân tích có $\mathrm{n}$ thành phần với diện tích pic là $S_{1}, S_{2}, \ldots S_{n}$ (A là một trong số $n$ thành phần trong tinh dầu) được tính theo công thức sau:

$$
\% \mathrm{~A}=\frac{\mathrm{S}_{\mathrm{A}}}{\mathrm{S}_{1}+\mathrm{S}_{2}+\ldots+\mathrm{S}_{\mathrm{n}}} \times 100
$$

Tác dụng chống oxy hóa DPPH:

1,1-diphenyl-2-picrylhydrazyl (DPPH) là chất tạo ra gốc tự do được dùng để sàng lọc tác dụng chống oxy hóa của các chất nghiên cứu. Hoạt tính chống oxy hóa thể hiện qua việc làm giảm màu của $\mathrm{DPPH}$, được xác định bằng cách đo quang ở bước sóng $\lambda=517 \mathrm{~nm}$. Tiến hành pha dung dịch DPPH có nồng độ $0,24 \mathrm{mg} / \mathrm{ml}$ trong methanol $(\mathrm{MeOH})$. Mẫu thử được pha loãng trong $\mathrm{MeOH}$ theo dãy nồng độ là $50 \mu \mathrm{g} / \mathrm{ml} ; 37,5$ $\mu \mathrm{g} / \mathrm{ml} ; 25 \mu \mathrm{g} / \mathrm{ml} ; 12,5 \mu \mathrm{g} / \mathrm{ml} ; 3,125 \mu \mathrm{g} / \mathrm{ml}$ (tinh dầu tỏi thu được bằng phương pháp $\mathrm{SCO}_{2}$ ) ; và theo dãy nồng độ $500 \mu \mathrm{g} / \mathrm{ml} ; 300 \mu \mathrm{g} / \mathrm{ml} ; 250$ $\mu \mathrm{g} / \mathrm{ml} ; 150 \mu \mathrm{g} / \mathrm{ml} ; 125 \mu \mathrm{g} / \mathrm{ml}$ (tinh dầu tỏi thu được bằng phương pháp cất kéo hơi nước). Lấy $450 \mu \mathrm{l}$ DPPH $0,24 \mathrm{mg} / \mathrm{ml}$ pha với $2550 \mu \mathrm{l}$ $\mathrm{MeOH}$ và $100 \mu \mathrm{g} / \mathrm{ml}$ mẫu thử đã được pha loãng trộn lẫn, bọc giấy bạc, ủ trong bóng tối. Để thời gian phản ứng 20 phút ở $25^{\circ} \mathrm{C}$, đọc mật độ hấp thụ của $\mathrm{DPPH}$ chưa phản ứng bằng máy đọc quang phổ Shimazhu UV-2600 ở bước sóng 517 nm. Phần trăm quét gốc tự do DPPH của mẫu thử được tính theo công thức sau:

$$
\% \text { chống oxy hóa }=\frac{A_{c}-A_{s}}{A_{c}} \times 100
$$

Trong đó: $\mathrm{A}_{\mathrm{c}}$ là độ hấp thụ quang của mẫu chuẩn (abs), $A_{s}$ là độ hấp thụ quang cuả dung dịch mẫu thử/ chứng (abs).

Mẫu chuẩn acid ascorbic tiến hành tương tự như mẫu thử với các nồng độ lần lượt là $2 \mu \mathrm{g} / \mathrm{ml}$; $1 \mu \mathrm{g} / \mathrm{ml} ; 0,5 \mu \mathrm{g} / \mathrm{ml} ; 0,25 \mu \mathrm{g} / \mathrm{ml} ; 0,125 \mu \mathrm{g} / \mathrm{ml}$; $0,0625 \mu \mathrm{g} / \mathrm{ml}$. IC 50 được tính theo giá trị \% chống oxy hóa tương quan với các nồng độ khác nhau của chất thử, thí nghiệm được lặp lại với $\mathrm{n}=3$.

\section{Kết quả nghiên cứu}

\subsection{Khảo sát các phuoong pháp chiết xuất tinh dầu tỏi}

Tiến hành chiết xuất tinh dầu tỏi (TDT) bằng phương pháp cất kéo hơi nước, chiết soxhlet với n-hexan và chiết bằng dung môi $\mathrm{CO}_{2}$ siêu tới hạn. Kết quả thể hiện như trong Bảng 1 .

Bảng 1 . Hình thức và hiệu suất chiết xuất TDT với các phương pháp chiết khác nhau $(\mathrm{n}=3)$

\begin{tabular}{|l|l|l|l|}
\hline Phương pháp & Cất kéo hơi nước & Chiết soxhlet & Chiết $\mathrm{SCO}_{2}$ \\
\hline Hình thức & Màu vàng đậm, mùi hắc & Màu vàng đậm, mùi hắc & $\begin{array}{l}\text { Màu vàng nhạt, mùi tươi tự } \\
\text { nhiên }\end{array}$ \\
\hline Hiệu suất (\%) & $0,113 \pm 0,003$ & $0,441 \pm 0,017$ & $0,465 \pm 0,012$ \\
\hline
\end{tabular}

Kết quả cho thấy khi chiết bằng các phương pháp khác nhau thì hiệu suất tinh dầu thu được thay đổi đáng kể, hiệu suất tinh dầu tỏi thu được của $\mathrm{SCO}_{2}$ là cao nhất $(0,465 \%)$, thấp nhất ở cất kéo hơi nước $(0,113 \%)$. Màu sắc và mùi vị của tinh dầu tỏi ở các phương pháp cũng khác nhau, chiết bằng $\mathrm{SCO}_{2}$ tinh dầu có màu vàng nhạt, mùi tỏi tươi tự nhiên; hai phương pháp còn lại tinh dầu có màu vàng đậm, mùi giống tỏi đã được nấu chín. Nguyên nhân có thể là do khi chiết xuất bằng cất kéo hoặc chiết soxhlet thì một số thành phần trong tinh dầu không bền với nhiệt nên tinh dầu thu được không còn giữ được mùi tươi tự nhiên. Kết quả này cũng tương tự như trong nghiên cứu của Bottini và cộng sự [8].

Do vậy phương pháp chiết xuất dùng dung môi $\mathrm{CO}_{2}$ siêu tới hạn được sử dụng trong các nghiên cứu tiếp theo. 
3.2. Khảo sát các điều kiện chiết xuất bà̀ng phương pháp sử dụng dung môi $\mathrm{CO}_{2}$ siêu tới hạn

\subsubsection{Khảo sát khoảng thời gian chiết xuất}

Tiến hành chiết TDT với các thông số quy trình như sau khối lượng tỏi là $200 \mathrm{~g}$; nhiệt độ $40^{\circ} \mathrm{C}$; áp suất: 200 bar; tốc độ dòng $\mathrm{CO}_{2}$ : $10 \mathrm{~g} / \mathrm{phút}$; thời gian chiết: $30,60,90,120,150$ phút. Kết quả như trong Hình 1.

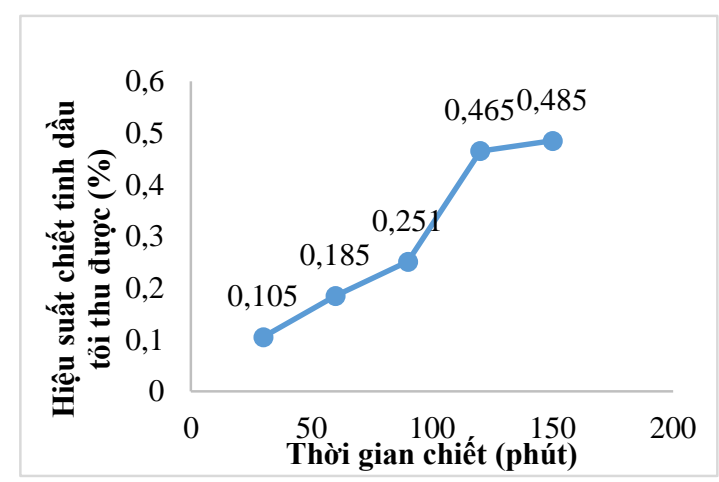

Hình 1. Hiệu suất chiết tinh dầu tỏi khi thay đổi thời gian chiết.

Khi tăng thời gian chiết thì hiệu suất TDT tăng lên. Tốc độ chiết tinh dầu tỏi giảm dần theo thời gian, lượng dầu chiết được ở thời điểm 120 phút và 150 phút tương đương nhau lần lượt là $0,465 \%$ và $0,485 \%$. Kết quả này cho thây sau 120 phút chiết xuất thì lượng tinh dầu trong tỏi gần như đã được chiết kiệt. Nguyên nhân là do càng về sau thì lượng tinh dầu trong tỏi càng ít đi, do vậy làm giảm tốc độ chiết TDT. Do vậy thời gian chiết xuất là 120 phút được lựa chọn.

\subsubsection{Khảo sát sự ảnh hưởng của áp suất chiết}

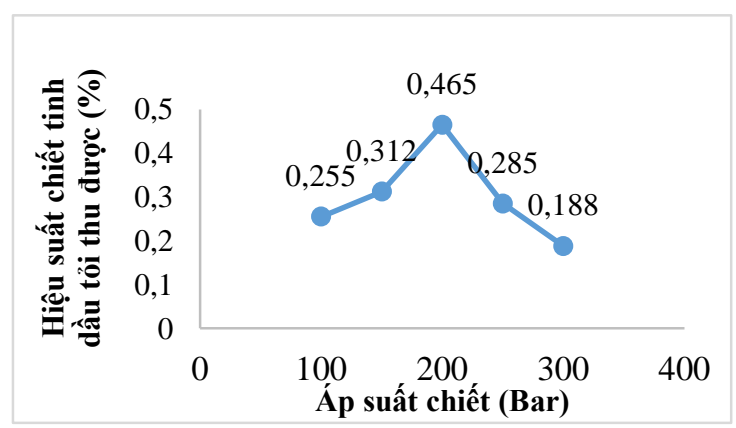

Hình 2. Hiệu suất chiết tinh dầu tỏi khi thay đổi thời gian chiết.
Tiến hành chiết TDT với các thông số quy trình như sau khối lượng tỏi $200 \mathrm{~g}$, nhiệt độ $40^{\circ} \mathrm{C}$, áp suất: 100,150,200, 250, 300 bar; tốc độ dòng $\mathrm{CO}_{2} 10 \mathrm{~g} /$ phút, thời gian chiết 120 phút. Kết quả được trình bày trong Hình 2 .

Kết quả cho thấy khi thay đổi áp suất chiết, hiệu suất tinh dầu tỏi thu được thay đổi đáng kể (hiệu suất TDT ở 100, 150, 200, 250, 300 bar lần lượt là $0,255 \% ; 0,312 \% ; 0,465 \% ; 0,285 \%$; $0,188 \%$ ) cao nhất là ở 200 bar. Khi giữ nhiệt độ ở $40^{\circ} \mathrm{C}$, tăng dần áp suất chiết thì tỷ trọng của $\mathrm{CO}_{2}$ tăng, tăng độ hòa tan tinh dầu trong dung môi [7]. Tuy nhiên khi chiết ở áp suất lớn hơn 200 bar thì sự ảnh hưởng của áp suất chiết tới hiệu suất của tinh dầu trong dung môi $\mathrm{CO}_{2}$ là giảm. Do vậy áp suất chiết xuất là 200 bar được lựa chọn.

\subsubsection{Khảo sát sự ảnh hưởng của nhiệt độ chiết}

Tiến hành chiết TDT với các thông số quy trình như sau khối lượng tỏi $200 \mathrm{~g}$; nhiệt độ $35^{\circ} \mathrm{C}$, $40^{\circ} \mathrm{C}, 50^{\circ} \mathrm{C}$; áp suất 200 bar; tốc độ dòng $\mathrm{CO}_{2}$ $10 \mathrm{~g} /$ phút; thời gian chiết 120 phút. Kết quả như trong Hình 3.

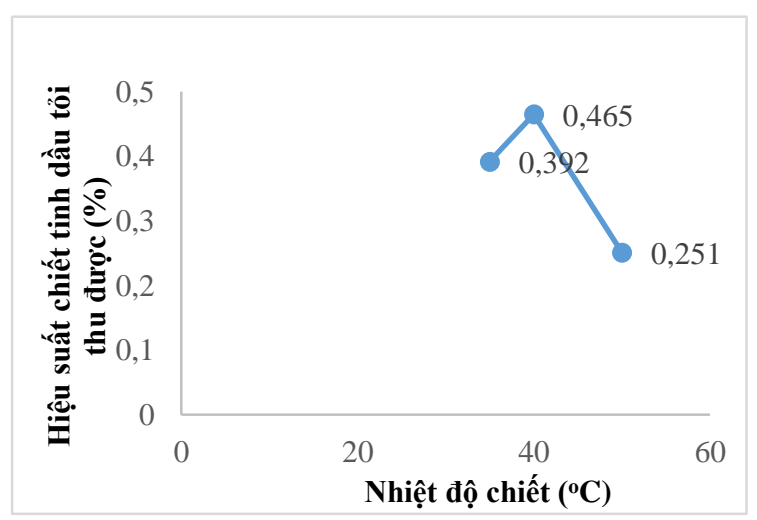

Hình 3. Hiệu suất chiết tinh dầu tỏi khi thay đổi nhiệt độ chiết.

Kết quả cho thấy hiệu suất chiết tinh dầu tỏi thu được tăng khi tăng từ nhiệt độ $35^{\circ} \mathrm{C}(0,392 \%)$ lên $40^{\circ} \mathrm{C}(0,465 \%)$, và sau đó giảm ở nhiệt độ $50^{\circ} \mathrm{C}(0,251 \%)$. Khi giữ áp suất chiết cao ở 200 bar, tăng nhiệt độ từ $40^{\circ} \mathrm{C}$ lên $50^{\circ} \mathrm{C}$ thì tỷ trọng $\mathrm{CO}_{2}$ giảm, do đó độ tan của tinh dầu trong dung môi và tốc độ khếch tán của $\mathrm{CO}_{2}$ vào tinh dầu giảm dẫn tới giảm hiệu suất chiết [9]. Hơn nữa, 
khi tăng nhiệt độ từ $40^{\circ} \mathrm{C}$ lên $50^{\circ} \mathrm{C}$ thì có thể ảnh hưởng tới các thành phần trong tinh dầu mà kém bền với nhiệt. Do đó nhiệt độ $40^{\circ} \mathrm{C}$ được lựa chọn.

Như vậy, điều kiện phương pháp chiết bằng dung môi $\mathrm{CO}_{2}$ siêu tới hạn được lựa chọn như sau: áp suất: 200 bar, nhiệt độ: $40^{\circ} \mathrm{C}$, tốc độ dòng $\mathrm{CO}_{2}: 10 \mathrm{~g} /$ phút, thời gian chiết xuất: 120 phút.

\subsection{Xác định tỷ lệ các thành phần chính trong tinh dầu tỏi}

Phân tích các mẫu tinh dầu tỏi bằng phương pháp sắc ký khí ghép nối khối phổ (GC-MS). Kết quả như trong Bảng 2.

Kết quả cho thấy các phương pháp chiết khác nhau thì tỷ lệ thành phần trong tinh dầu cũng khác nhau. 5 thành phần chính trong các mẫu TDT là diallyl sulfid, diallyl disulfid, 3-vinyl-1,2- dithiacyclohex-4-en, 3-vinyl-1,2-dithiacyclohex5-en và diallyl trisulfid. Phương pháp cất kéo hơi nước và chiết soxhlet thì chất chính trong tinh dầu lần lượt là diallyl disulfid và diallyl trisulfid còn chiết xuất bằng dung môi $\mathrm{CO}_{2}$ siêu tới hạn thì 3vinyl-1,2-dithiacyclohex-5-en chiếm tỷ lệ nhiều nhất trong TDT. Nguyên nhân là do trong quá trình chiết xuất ở nhiệt độ cao thì allicin trong tỏi bị nhiệt phân hủy mạnh thành các hợp chất diallyl sulfid, trong khi đó phương pháp $\mathrm{SCO}_{2}$ chiết xuất ở nhiệt độ $40^{\circ} \mathrm{C}$ nên tỷ lệ các hợp chất diallyl sulfid chiếm ít hơn khá nhiều [10,11]. Ngoài ra chiết xuất $\mathrm{SCO}_{2}$ thì allicin bị chuyển hóa chủ yếu là các hợp chất 3-vinyl-1,2-dithiacyclohex-5-en và 3-vinyl-1,2-dithiacyclohex-4-en, đây là các hợp chất tạo nên mùi thơm đặc trưng cho tinh dầu tỏi khi so sánh với 2 phương pháp chiết xuất còn lại [12].

Bảng 2. Tỷ lệ thành phần chính trong tinh dầu tỏi trong các phương pháp chiết khác nhau

\begin{tabular}{|l|l|l|l|}
\hline Các chất chính trong tinh dầu tỏi & Cất kéo hơi nước & $\begin{array}{l}\text { Chiết soxhlet với } \\
\text { n-hexan }\end{array}$ & $\begin{array}{l}\text { Chiết } \mathrm{SCO}_{2}(200 \text { bar, } \\
\left.40^{\circ} \mathrm{C}\right)\end{array}$ \\
\hline Diallyl sulfid (\%) & 4,23 & 0,31 & 1,94 \\
\hline Diallyl disulfid (\%) & 32,48 & 20,05 & 10,93 \\
\hline 3-Vinyl-1,2-dithiacyclohex-4-en (\%) & 2,77 & 8,79 & 19,52 \\
\hline 3-Vinyl-1,2-dithiacyclohex-5-en (\%) & 10,54 & 15,3 & 31,67 \\
\hline Diallyl trisulfid (\%) & 13,77 & 28,73 & 3,09 \\
\hline
\end{tabular}

3.4. Đánh giá tác dụng chống oxy hóa của tinh dầu tỏi

Tiến hành đánh giá tác dụng chống oxy hóa của TDT chiết xuất từ cất kéo hơi nước và $\mathrm{SCO}_{2}$ với mẫu chứng dương là acid ascorbic. Kết quả như Hình 4,5 và 6 và Bảng 3 .

Bảng 3. Giá trị $\mathrm{IC}_{50}$ của các mẫu tinh dầu và acid ascorbic $(n=3)$

\begin{tabular}{|l|l|l|l|}
\hline Mẫu & $\begin{array}{l}\text { Cất kéo } \\
\text { hơi nước }\end{array}$ & $\mathrm{SCO}_{2}$ & $\begin{array}{l}\text { Acid } \\
\text { ascorbic }\end{array}$ \\
\hline $\begin{array}{l}\text { Giá trị } \\
\begin{array}{l}\mathrm{IC}_{50} \\
(\mu \mathrm{g} / \mathrm{ml})\end{array}\end{array}$ & $\begin{array}{l}438,77 \\
\pm 7,43\end{array}$ & $\begin{array}{l}37,68 \\
\pm 1,25\end{array}$ & $\begin{array}{l}0,22 \\
\pm 0,01\end{array}$ \\
\hline
\end{tabular}

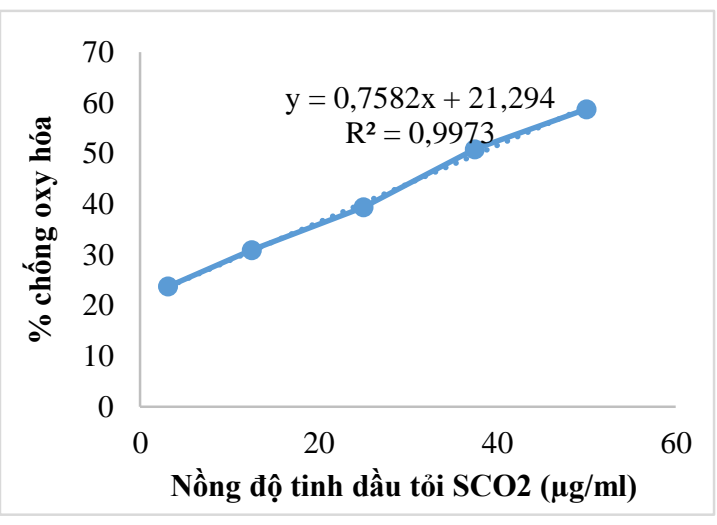

Hình 4. Đồ thị biểu diễn khả năng chống oxy hóa của TDT chiết bằng phương pháp $\mathrm{SCO}_{2}$. 


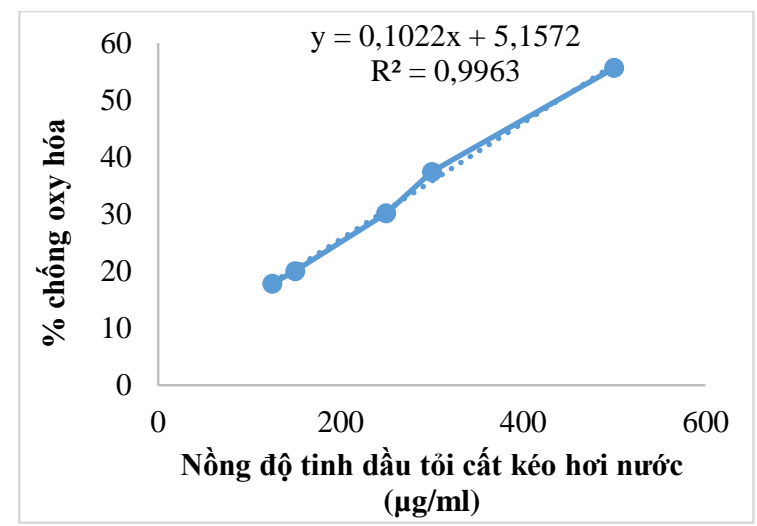

Hình 5. Đồ thị biểu diễn khả năng chống oxy hóa của TDT thu được bằng cất kéo hơi nước.

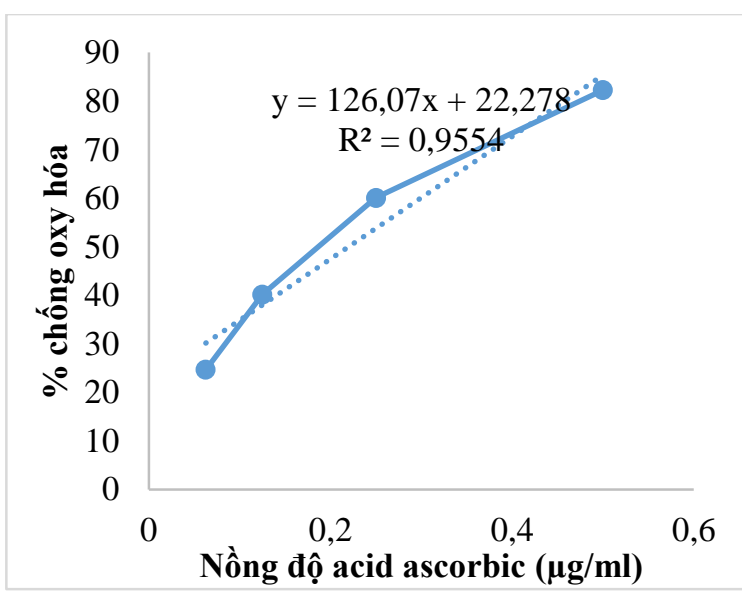

Hình 6. Đồ thị biểu diễn khả năng chống oxy hóa của acid ascorbic.

Kết quả cho thấy giá trị $\mathrm{IC}_{50}$ của TDT chiết bằng $\mathrm{SCO}_{2}(37,68 \mu \mathrm{g} / \mathrm{ml})$ thấp hơn chiết bằng cất kéo hơi nước 11,64 lần $(438,77 \mu \mathrm{g} / \mathrm{ml})$ và cao hơn acid ascorbic $(0,22 \mu \mathrm{g} / \mathrm{ml})$ khoảng 171 lần. Hoạt tính chống oxy hóa của tinh dầu tỏi chiết xuất được là do trong tinh dầu tỏi có chứa các hợp chất chứa lưu huỳnh như diallyl sulfid, diallyl disulfid, 3-vinyl-1,2-dithiacyclohex-4en, 3-vinyl-1,2-dithiacyclohex-5-en và diallyl trisulfide $[13,14]$.

Ngoài ra, mẫu TDT chiết xuất bằng phương pháp $\mathrm{SCO}_{2}$ có khả năng chống oxy hóa tốt hơn phương pháp cất kéo hơi nước. Nguyên nhân có thể do một số thành phần có hoạt tính chống oxy hóa trong tinh dầu tỏi bị tác động, không bền với nhiệt nên tác dụng chống oxy hóa bị giảm. Như vậy tinh dầu tỏi chiết xuất bằng dung môi $\mathrm{CO} 2$ siêu tới hạn có hoạt tính chống oxy hóa tốt hơn phương pháp cất kéo hơi nước. Tuy nhiên hoạt tính chống oxy hóa vẫn yếu khi so sánh với acid ascorbic, điều này phù hợp với nghiên cứu của Mohsen Barzegar và cộng sự [15].

\section{Kết luận}

Nghiên cứu đã chiết xuất được tinh dầu tỏi, đặc biệt là khi sử dụng phương pháp chiết $\mathrm{SCO}_{2}$. Khảo sát các điều kiện tách chiết $\mathrm{SCO}_{2}$ đã xác định được điều kiện chiết xuất hiệu quả: áp suất 200 bar, nhiệt độ $40^{\circ} \mathrm{C}$, tốc độ dòng $10 \mathrm{~g} /$ phút, thời gian chiết 2 giờ, hiệu suất chiết tinh dầu khoảng $0,465 \%$. Các thành phần chính trong các mẫu tinh dầu tỏi là diallyl sulfid, diallyl disulfid, 3-vinyl-1,2-dithiacyclohex-4-en, 3-vinyl-1,2dithiacyclohex-5-en và diallyl trisulfid. Khả năng chống oxy hóa của tinh dầu tỏi chiết $\mathrm{SCO}_{2}$ cao gấp 11,64 lần so với phương pháp cất kéo hơi nước, tuy nhiên vẫn còn thấp khi so sánh với acid ascorbic.

\section{Tài liệu tham khảo}

[1] R. Lawrencea, K. Lawrenceb, Antioxidant activity of garlic essential oil (Allium Sativum) grown in north Indian plains, Asian Pacific Journal of Tropical Biomedicine 1 (2011) 51-54. https://doi.org/10.1016/S2221-1691(11)60122-6.

[2] Dziri, H. Casabianca, B. Hanchi, K. Hosni, Composition of garlic essential oil (Allium sativum L.) as influenced by drying method, Journal of Essential Oil Research 26 (2014) 91-96. https://doi.org/10.1080/10412905.2013.868329.R.

[3] Li, W. Chen, W. Wang, W. Tian, X.Z. Rrui, Extraction of essential oils from garlic (Allium sativum) using ligarine as solvent and its immunity activity in gastric cancer rat, Medicinal Chemistry Research $19 \quad$ (2010) 1092-1105. https://doi.org/10.1007/s00044-009-9255-z.

[4] M.K. Gafar, A.U. Itodo, A. A. Warra, L. Abdullahi, Extraction and Physicochemical Determination of Garlic (Allium sativum L) Oil, International Journal of Food and Nutrition science 1 (2012) 4-7. 
[5] A.P. Sa'nchez-Camargo, J.A. Mendiola, E. Iba'ñez, M. Herrero, Supercritical Fluid Extraction, Reference Module in Chemistry, Molecular Sciences and Chemical Engineering (2014) 1-17. https://doi.org/10.1016/b978-0-12409547-2.10753-x.

[6] A. Rafe, M.S. Nadjafi, Physicochemical characteristics of garlic (Allium sativum L.) oil: Effect of extraction procedure, International Journal of Nutrition and Food Sciences 3 (2014) 1-5. https://doi.org/10.11648/j.ijnfs.s.2014030601.11.

[7] J.M. del Valle, C. Mena, M. Budinich, Extraction of garlic with supercritical $\mathrm{CO}_{2}$ and conventional organic solvents, Brazilian Journal of Chemical Engineering, 25 (2008) 535-542. https://doi.org/10.1590/S0104-66322008000300011.

[8] A.E. Andreatta, G. Foco, G. Mabe, S.B. Bottini, Extraction of garlic oil with quasi-critical solvents, 4th Mercosur Congress on Process Systems Engineering (2014) 1-9.

[9] H. Kamali, N. Aminimoghadamfarouj, E. Golmakani, A. Nematollahi, The optimization of essential oils supercritical $\mathrm{CO} 2$ extraction from Lavandula hybrida through static-dynamic steps procedure and semi-continuous technique using response surface method, Pharmacognosy Res 7 (2015) 57-65. https://doi.org/10.4103/09748490.147209.

[10] L.D. Lawson, Z.J. Wang, B.G. Hughes, Identification and HPLC quantitation of the sulfides and dialk(en)yl thiosulfinates in commercial garlic products, Planta Med, 57 (1991) 363-370. https://doi.org/10.1055/s-2006-960119.

[11] E. A. O'Gara, D. J. Hill, D. J. Maslin, Activities of Garlic Oil, Garlic Powder, and Their Diallyl Constituents against Helicobacter pylori, Applied and Environmental Microbiology 66 (2000) 22692273. https://doi.org/10.1128/aem.66.5.22692273.2000.

[12] X. Qiao, Molecular distillation separation and purification of essential oils of garlic, Food science Shandong 5 (2007) 60.

[13] M. Iranshahi, A review of volatile sulfurcontaining compounds from terrestrial plants: biosynthesis, distribution and analytical methods, The Journal of Essential Oil Research, 24 (2012) 393-434. https://doi.org/10.1080/10412905.2012.692918.

[14] M. Corzo-Martı'nez, N. Corzo, M. Villamiel, Biological properties of onions and garlic, Trends in Food Science \& Technology 18 (2007) 609-625. https://doi.org/10.1016/j.tifs.2007.07.011.

[15] K. Khoshtinat, M. Barzegar, M. A. Sahari, Z. Hamidi, Comparison of Antioxidant and Antibacterial Activities of Free and Encapsulated Garlic Oil with Beta-cyclodextrin, Applied food biotechnology 3 (2016) 254-268. https://doi.org/10.22037/afb.v3i4.12631. 